\title{
Neoadjuvant chemotherapy against newly diagnosed CNS germ-cell tumors: A case report
}

\author{
Mehrnosh Aeinfar ${ }^{1}$, Mehrdad Payandeh ${ }^{1}$, Mohammad Samadian ${ }^{2}$, Nasrin Amiryfard ${ }^{3}$, \\ Mohammaderfan Zare ${ }^{4}$, Mohammadebrahim Soltany ${ }^{5}$, Masoud Sadeghi ${ }^{6}$, Edris Sadeghi ${ }^{6}$ \\ 1. Department of Medical Oncology, Kermanshah University of Medical Science (KUMS), Kermanshah, I ran. 2. Department \\ of neurosurgery oncology of Day hospital, Tehran University of Medical Science (TUMS), Tehran, Iran. 3. Department of \\ radiotherapy Oncology, KUMS, Kermanshah, Iran. 4. Student research center, KUMS, Kermanshah, Iran. 5. Department \\ of blood transfusion center, KUMS, Kermanshah, Iran. 6. Medical Biology Research Center, KUMS, Kermanshah, Iran.
}

Correspondence: Mehrdad Payandeh, MD, Hematologist-Medical Oncologist. Address: Kermanshah University of Medical Science (KUMS), Kermanshah, Iran. Email: md.payandeh@yahoo.com

Received: September 28, 2013

Accepted: January 9, $2015 \quad$ Online Published: January 30, 2015

DOI : $10.5430 /$ jst.v5n1p18

URL: http://dx.doi.org/10.5430/jst.v5n1p18

\section{Abstract}

Intracranial germ cell tumors (GCTs) are rare brain tumors that typically arise in the pineal or suprasellar regions. A young man (22 years old) was presented with complaint of one year of headache, and recently vomiting, and in exam papilledema, lethargy, somnolence, diabetes insipidus. A Phase II trial with carboplatin based regimen was conducted in this newly diagnosed patient histologically and was confirmed radiologically evaluable CNS germinomas before they received radiotherapy. This patient was presented with a localized hypothalamic germinoma and had a CR after two courses of carboplatin based regimen (the CEB regimen). He received $30 \mathrm{~Gy}$ of involved field radiotherapy and now at end of treatment after three months is well being without any sign of relapse. Neoadjuvant chemotherapy carboplatin based regimen was highly active in treating newly diagnosed CNS germinomas. Further chemotherapy studies eventually may permit additional dose reductions and/or elimination of radiotherapy for patients with CNS germinomas.

\section{Key words}

Diabetes insipidus, Germ cell, Neoadjuvant chemotherapy

\section{I ntroduction}

Germ cell tumors (GCTs) are heterogeneous groups of neoplasm with diverse variation in age, site, clinical presentation, histopathological features, and treatment modalities. Extragonadal GCTs constitute only 1\%-5\% of all GCTs, and are very rare $^{[1]}$.

Approximately $20 \%$ to $40 \%$ of patients with GCTs will need advanced medical treatment because of relapse or initial metastatic disease ${ }^{[2]}$. The GCTs represent the most common cancer in men aged $15-35$ years ${ }^{[3]}$, and they compromise $15 \%-20 \%$ of all anterior mediastinal tumors and benign mediastinal teratomas accounts for $60 \%$ of all germ cell tumors ${ }^{[4]}$.

In the present study we report a patient man who was diagnosed with CNS germinomas before he received radiotherapy and neoadjuvant chemotherapy carboplatin based regimen was performed for him. 


\section{Case report}

Young man with 22 years was presented with complaint of one year of headache, and recently vomiting, and in exam papilledema, lethargy, somnolence, diabetes insipidus (DI). On MRI, supracellar isointense mass that appear in third ventricle and hypothalamus (see Figure 1). The CT scan of chest and abdomen was normal.
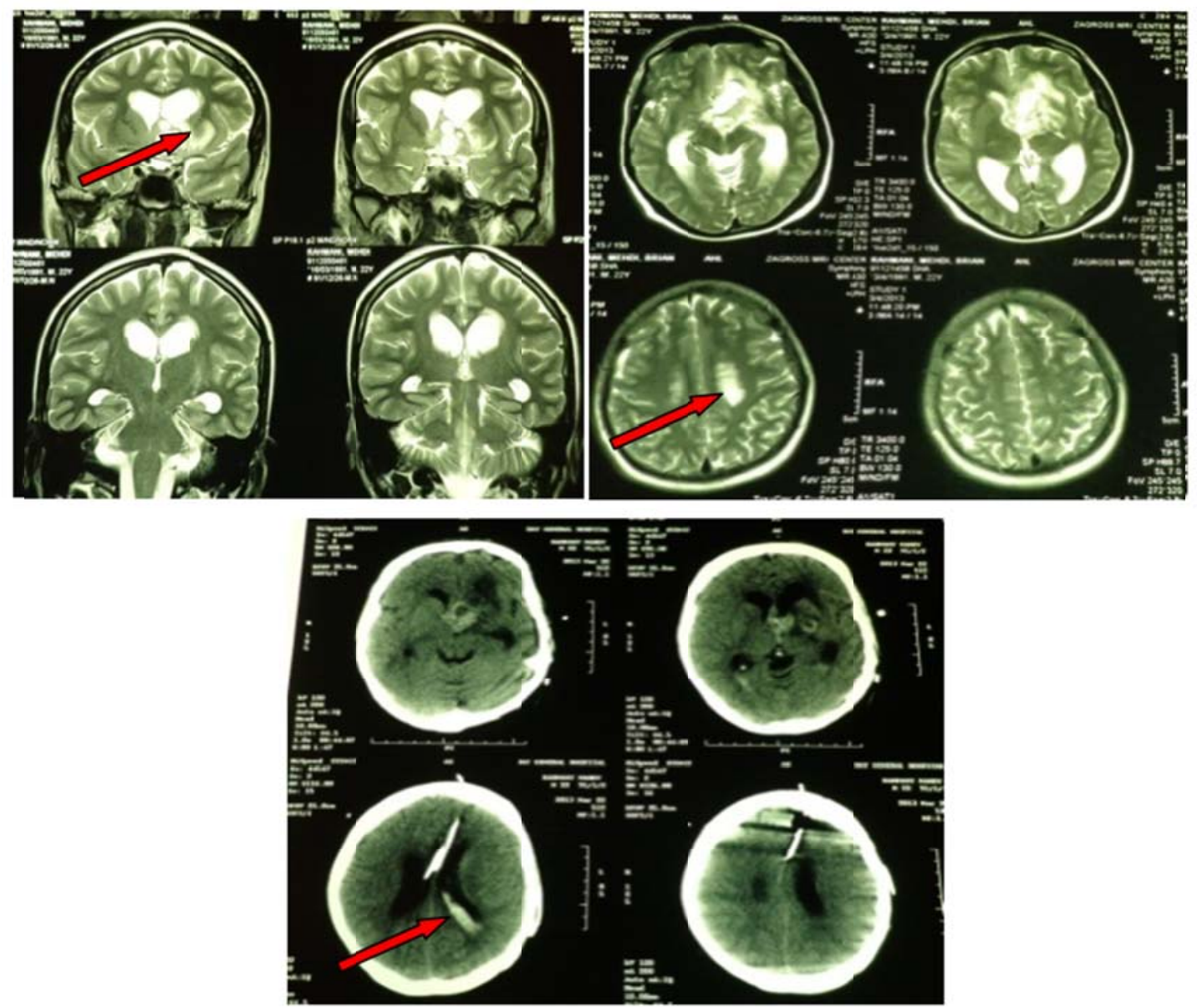

Figure 1. On Brain MRI (axial and coronal) and Brain CT SCAN, supracellar isointense mass that appear in the third ventricle and hypothalamus and shunt effect was seen.

Open surgical biopsy was done and right ventricular shunt taken, for obstructive hydrocephalus. In gross pathology, pure germinoma was recommend and established by immunostain results: PLAP and C-KIT were positive, GAFP and LCA were negative.

Patient gave written informed consent in accordance with the declaration of Helsinki. A Phase II trial with carboplatin based regimen was conducted in this newly diagnosed patient histologically and was confirmed radiologically evaluable CNS germinomas before he received radiotherapy. He had normal cerebrospinal fluid and in cytology was negative and in CSF analysis all tumor markers consist of B-HCG, LDH, AFP were in normal range. Serum tumor markers (human chorionic gonadotropin [HCG] and alpha fetoprotein [AFP] were normal) but only LDH was $>1,171$ IU/L. This patient had a localized tumor in the third ventricle and hypothalamus. Two courses of carboplatin based regimen (the CEB regimen) consisted of carboplatin (target AUC of $5 \mathrm{mg} / \mathrm{ml} \times \mathrm{min}$ ) on first day, etoposide $100 \mathrm{mg} / \mathrm{m}^{2}$ on days 1 to 5 and bleomycin $30 \mathrm{mg}$ on days 1,8 and 15 . After first course of treatment vomiting, lethargy and somnolence significantly decreased and in phondoscopic examination papilledema resolved. The response was evaluated after two courses by imaging study. This patient had a complete response to this classic BEP chemotherapy regimen. After 4 months later of 
beginning the patient's response was reevaluated. The radiotherapy volume was determined by the extent of disease at diagnosis (i.e., localized disease was treated with an involved field). An MRI obtained six months later, not seen any mass lesion (see Figure 2).

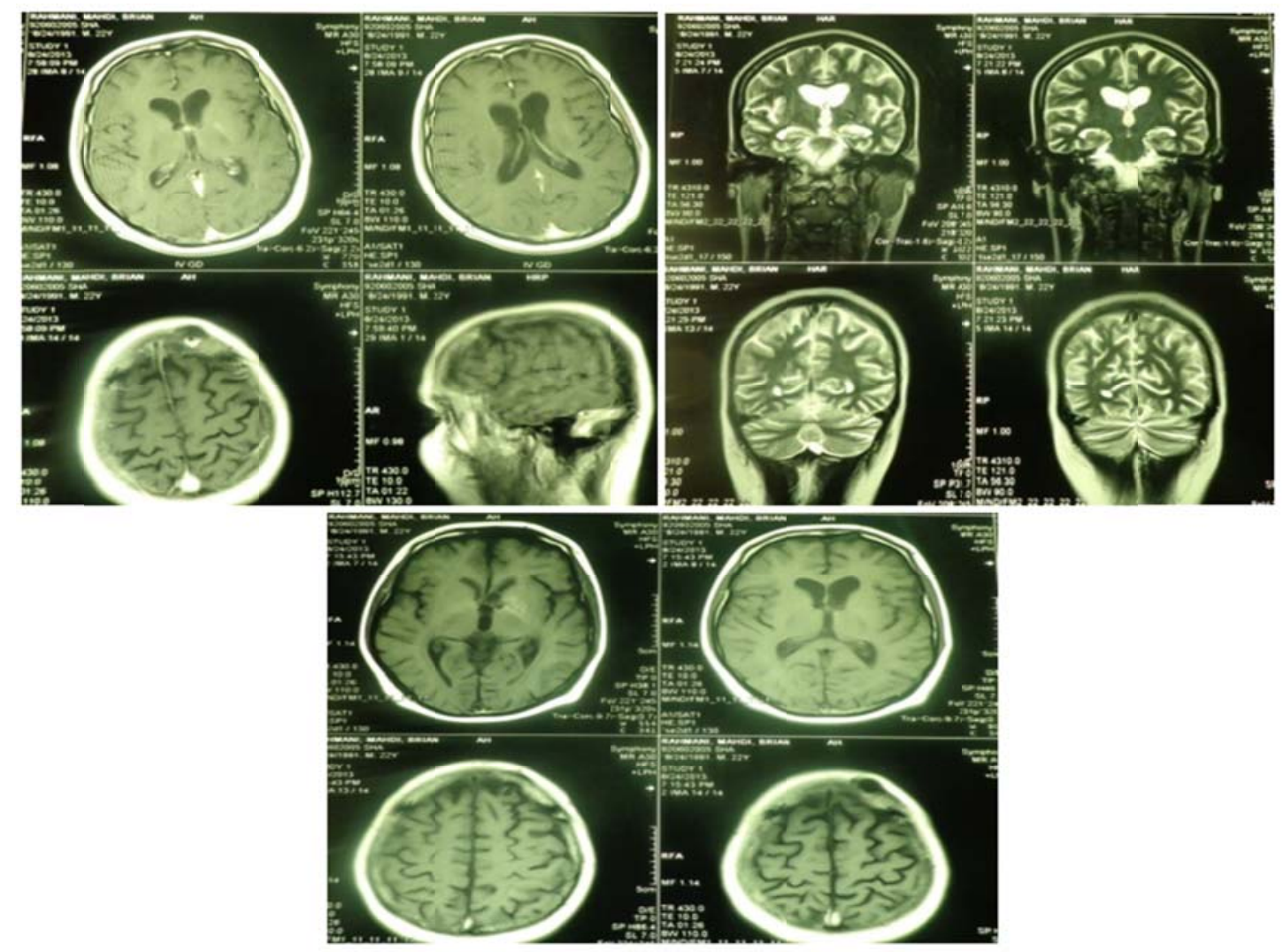

Figure 2. A MRI (axial and coronal panel) just above that obtained after ten months of first course of treatment, not seen any mass lesion or local effects that previously exist.

\section{Discussion}

GCTs are rare and heterogeneous with very little is known about their pathogenesis and underlying genetic abnormallities ${ }^{[5]}$. Histologic examination is needed to establish a definitive diagnosis of an intracranial GCT and to ascertain the histologic subtype. On MRI, intracranial GCTs appear isointense or hypointense on T1 sequences and hyperintense on T2 sequences ${ }^{[6]}$. The GCTs can be divided into major groups including germinomas and nongerminomatous GCTs (NGGCTs) ${ }^{[7]}$, and these imaging characteristics of the histologic subtypes are similar, and MRIs cannot reliably distinguish germinomas from NGGCTs ${ }^{[8]}$. The MRI of the entire spine that was normal to this case is imperative for adequate staging of intracranial GCTs, since 10 to 15 percent of patients will have leptomeningeal spread diagnosis ${ }^{[6,9]}$. Pure germinomas are exquisitely sensitive to radiation therapy, a gross total resection of localized germinomas is generally not recommended because of the risk of surgical complications and because pure germinomas are exquisitely sensitive to radiation therapy, intracranial germinomas are exquisitely sensitive to radiation. Most contemporary series have reported long-term progression free survival (PFS) rates $>90$ percent for children with localized, pure germinomas after radiation therapy (RT) alone ${ }^{[10-12]}$. Platinum-based chemotherapy regimens have a high level of activity against extracranial GCTs in children ${ }^{[13]}$. Eight of 10 recurrences occurred outside the RT field, in the periventricular area ${ }^{[14]}$. In the SIOP CNS GCT 96 study, 183 patient with localized germinomas received either chemotherapy plus 40 Gy focal RT or 24 Gy CSI with a 16 Gy tumor boost without chemotherapy ${ }^{[15]}$. The recurrence rate was higher in patients who received chemotherapy plus focal RT compared to those who received chemotherapy plus whole ventricle RT (28 versus 6 percent). The benefit of 
gross total tumor resection in localized NGGCTs has not been established; several large series have not confirmed that macroscopic tumor resection improves the final outcome of patient with intracranial NGGCT ${ }^{[16,17]}$.

Although these tumors are sensitive to chemotherapy, the role of neoadjuvant chemotherapy to allow a more limited, focal RT field remains unproven, and this approach should be restricted to patients participating in formal clinical trials. The optimal chemotherapy regimen has not been defined. The available data indicate that platinum-based regimens, such as those used in other gonadal and extragonadal germ cell tumors, are effective. Available data indicate that RT is an essential component of initial treatment. Whether craniospinal irradiation is required or whether whole ventricle RT is sufficient is uncertain in patient with localized NGGCTs.

\section{Conclusion}

In patients with residual masses after chemotherapy and RT, second look surgery should be strongly considered. Patients with both germinomas and NGGCTs should be encouraged to participate in prospective clinical trials whenever possible. Neoadjuvant chemotherapy carboplatin based regimen was highly active in treating newly diagnosed CNS germinomas. Further chemotherapy studies eventually may permit additional dose reductions and/or elimination of radiotherapy for patients with CNS germinomas.

\section{Conflict of interests}

The authors declare no conflict of interests in this study.

\section{References}

[1] Pawar NP, Mahajan SV, Chaudhari RA, Chavan SD. Extragonadal GCT: a rare case report of sacrococcygeal pure yolk sac tumor. Indian J Pathol Microbiol. 2013 Jul-Sep; 56(3): 329-31. PMid:24152532 http://dx.doi.org/10.4103/0377-4929.120421

[2] Haugnes HS, Stephenson AJ, Feldman DR. Beyond stage I germ cell tumors: current status regarding treatment and long-term toxicities. Am Soc Clin Oncol Educ Book. 2014; 34: e180-90. PMid:24857101 http://dx.doi.org/10.14694/EdBook_AM.2014.34.e180

[3] Arafat W, Albany C, Ulbright TM, Foster R, Einhorn LH. Very late relapse of germ cell tumor as a teratoma: a case report and review of the literature. J Surg Case Rep. 2014 Jun 2; 2014(6). PMid:2488742

[4] Dalal U, Jora MS, Dalal AK, Attri AK, Singal R, Gupta S. Primary germ cell tumor of the mediastinum - presenting as a huge mass. Int J Prev Med. 2014 Feb; 5(2): 230-2. PMid:24627752

[5] Terashima K, Yu A, Chow WY, Hsu WC, Chen P, Wong S, et al. Genome-wide analysis of DNA copy number alterations and loss of heterozygosity in intracranial germ cell tumors. Pediatr Blood Cancer. 2014 Apr; 61(4): 593-600. PMid:24249158 http://dx.doi.org/10.1002/pbc.24833

[6] Jack M Su. Pediatric intracranial germ cell tumors. Available from: http://firedrops.centelia.net/uptodate/contents/mobipreview.htm?29/25/30105/abstract /68

[7] Rana C, Krishnani N, Kumar R. Intracranial germ cell tumors at unusual locations. J Postgrad Med. 2012 Oct-Dec; 58(4): $286-9$. PMid:23298924 http://dx.doi.org/10.4103/0022-3859.105449

[8] Liang L, Korogi Y, Sugahara T, Ikushima I, Shigematsu Y, Okuda T, et al. MRI of intracranial germ-cell tumours. Neuroradiology. 2002 May; 44(5): 382-8. PMid:12012121 http://dx.doi.org/10.1007/s00234-001-0752-0

[9] Packer RJ, Cohen BH, Cooney K. Intracranial germ cell tumors. Oncologist. 2000; 5(4): 312-20. PMid:10964999

[10] Wolden SL, Wara WM, Larson DA, Prados MD, Edwards MS, Sneed PK. Radiation therapy for primary intracranial germ-cell tumors. Int J Radiat Oncol Biol Phys.1995 Jul 15; 32(4): 943-9. http://dx.doi.org/10.1016/0360-3016(95)00067-9

[11] Sawamura Y, Ikeda J, Shirato H, Tada M, Abe H. Germ cell tumours of the central nervous system: treatment consideration based on 111 cases and their long-term clinical outcomes. Eur J Cancer. 1998 Jan; 34(1): 104-10. http://dx.doi.org/10.1016/S0959-8049(97)10045-4

[12] Jensen AW, Laack NN, Buckner JC, Schomberg PJ, Wetmore CJ, Brown PD. Long-term follow-up of dose-adapted and reduced-field radiotherapy with or without chemotherapy for central nervous system germinoma. Int J Radiat Oncol Biol Phys. 2010 Aug 1; 77(5): 1449-56. PMid:20045266 http://dx.doi.org/10.1016/j.ijrobp.2009.06.077 
[13] Alapetite C, Patte C, Frappaz D, Sainte-Rose C, Kieffer R, Raquin MA, et al. Long-term follow-up of intracranial germinoma treated with primary chemotherapy followed by focal radiation treatment: The SFOP-90 experience. Neurooncol. 2005 ; 7: 517.

[14] Alapetite C, Brisse H, Patte C, Raquin MA, Gaboriaud G, Carrie C, et al. Pattern of relapse and outcome of non-metastatic germinoma patients treated with chemotherapy and limited field radiation: the SFOP experience. Neuro Oncol. 2010 Dec; 12(12): 1318-25. PMid:20716594

[15] Tamaki N, Lin T, Shirataki K, Hosoda K, Kurata H, Matsumoto S, et al. Germ cell tumors of the thalamus and the basal ganglia. Childs Nerv Syst. 1990 Jan; 6(1): 3-7. PMid:2178773 http://dx.doi.org/10.1007/BF00262257

[16] Kim DI, Yoon PH, Ryu YH, Jeon P, Hwang GJ. MRI of germinomas arising from the basal ganglia and thalamus. Neuroradiology. 1998 Aug; 40(8): 507-11. PMid:9763338 http://dx.doi.org/10.1007/s002340050634

[17] Matsutani M, Japanese Pediatric Brain Tumor Study Group. Combined chemotherapy and radiation therapy for CNS germ cell tumors--the Japanese experience. J Neurooncol. 2001 Sep; 54(3): 311-6. PMid:11767296

http://dx.doi.org/10.1023/A:1012743707883 